\title{
Augmented Cream Dosage Form
}

National Cancer Institute

\section{Source}

National Cancer Institute. Augmented Cream Dosage Form. NCI Thesaurus. Code C60897.

A cream that is modified to enhance the release of active and/or inert ingredient(s). 